\title{
LA DEMOCRACIA EN LA SOCIEDAD ORGANIZADA
}

\section{Mercedes Ávila*}

Con el término democracia nos podemos referir a un conjunto particular de instituciones y prácticas políticas, un cierto cuerpo de doctrinas jurídicas, un orden económico y social, un sistema que asegura el logro de ciertos resultados deseables, una serie de valores que deben garantizarse a través de instituciones, un proceso singular para la toma de decisiones, etc.

Las organizaciones se definen como "formaciones sociales orientadas hacia fines concretos"1. En la sociedad actual, las organizaciones se conciben como un medio de ordenación y como un elemento de la dinámica social necesario. Para analizar y comprender la estructura y el funcionamiento de la sociedad actual debemos tener en cuenta las organizaciones. Cada etapa vital del individuo suele estar fuertemente condicionada por alguna organización, piénsese, por ejemplo, en la escuela, la universidad, la empresa, etc.

Para Mayntz $z^{2}$, "uno de los condicionantes estructurales más importantes del desarrollo de las organizaciones lo encontramos en la ordenación política de una sociedad", y dentro de ésta, en la centralización y en la democratización, que devienen, por tanto, en los dos principios estructurales más decisivos.

La demolición de la estructura social y la formación del Estado de gran espacio (Flächenstaat), con su autoridad centralizada, determinaron esencialmente la historia de la Administración y del ejército, e influyeron también en la de la Iglesia, la escuela, el hospital, la prisión e incluso (y no en último lugar) sobre la

- Profesora de Sociología de la Universidad de Castilla-La Mancha. 
industrialización, que a su vez condujo a la empresa moderna.

Ya Tocqueville y Durkheim destacaron el papel de las asociaciones voluntarias como intermediadoras entre el individuo y el Estado. Para algunos autores las asociaciones voluntarias constituyen una forma de facilitar la participación política de los ciudadanos, a la vez que un importante factor de integración para los individuos, por lo que supondrían una forma de profundización y perfeccionamiento de la democracia. Pero la organización también es uno de los medios más eficaces para asegurar el control de los individuos $^{3}$, por lo que la proliferación de las organizaciones, incluidas las asociaciones voluntarias, podría terminar convirtiéndose en una perversión democrática al favorecer los particularismos, la reproducción de la desigualdad y el control por parte de determinadas élites.

\section{SIGNIFICADOS DE DEMOCRACIA}

\section{La democracia ateniense}

Se suele decir que la democracia como forma de organización política nació en la Grecia Antigua, en Atenas y Siracusa sobre todo, y su origen deriva de la lucha interna dentro de las aristocracias ${ }^{4}$. Para los antiguos democracia equivalía a gobierno de los muchos. Aristóteles en su Política dice que hay democracia cuando los libres y pobres, siendo muchos, tienen el control del poder ${ }^{5}$. En estas democracias había una igualdad al menos de principio en el control del poder, y una igualdad mayor o menor en su ejercicio.

En la democracia ateniense, los ciudadanos reunidos en asamblea constituían el gobierno, de tal forma que gobierno y ciudadanos eran una y la misma cosa. A esta forma de democracia se la llamó después democracia directa.

Rodríguez Adrados ${ }^{6}$, sitúa el comienzo de la historia de la democracia en la reforma de Solón ${ }^{7}$, si bien entonces no se habla de demokratía, sino de eunomía o "buen gobierno" o "buena legislación". Esto implica una restricción del poder: la justicia, que debe imponerse por encima de todos. Del ideal de la eunomía o "buenas leyes" se pasará (con Clístenes) al de la isonomía o "mismas leyes" para todos, y de aquí a la demokratía, o gobierno del pueblo, "pueblo" en el sentido de opuesto a los "pocos", "los mejores", "los poderosos". Para los sofistas la democracia es el resultado del logos o razón, que es común a todos los hombres y que hace posible el acuerdo y la solución de los problemas entre los hombres.

La democracia clásica se basa en las siguientes ideas y valores ${ }^{8}$ :

a) La areté o virtud: valores como los del autocontrol, respeto, compasión, piedad, generosidad, etc, eran considerados buenos y daban prestigio. La democracia niega la naturaleza excepcional de la aristocracia o la nobleza, así como su 
superioridad moral: cualquier ateniense podía y debía aspirar a tener las virtudes del noble, virtudes que servían para justificar y legitimar su poder y riqueza, también superiores. De aquí a la idea de igualdad sólo hay un paso. Mucho más tarde, en el segundo tercio del siglo XIX, Tocqueville, en su análisis de La democracia en América, también defenderá la necesidad de moralidad para el buen funcionamiento de los pueblos democráticos.

b) La dike o justicia como lo contrario del abuso y la violencia (hybris). Se trata de justicia en el sentido de equilibrio: equilibrio entre las clases y equilibrio en el interior de las clases: "es hermosa la igualdad, el exceso y el defecto no me parecen bien", dirá Protágoras ${ }^{9}$. También Aristóteles defenderá este tipo de equilibrio, basado en el punto medio. Aquí por tanto se establece una relación en cierto sentido entre justicia e igualdad. También Tocqueville destacará este tipo de igualdad basada en el punto medio, que concibe a la vez como un efecto y uno de los factores que hace posible la democracia.

c) El nomos o la ley, entendido como costumbre institucionalizada y obligatoria legalmente, y que sería una forma de garantizar la justicia. Es decir, la ley debe estar para lograr la justicia. Pero ley no es sinónimo de justicia. Es más, la ley, aun siendo la misma para todos (todas las clases se rigen por la misma ley), puede producir injusticia, puede llegar un momento que provoque situaciones injustas.

Con el tiempo fueron extendiéndose ideas como que todo podía ser discutido y cuestionado, y que el nomos o costumbre tradicional era cosa de convención, por lo que era tan justa la de los griegos como la de los bárbaros, o la de los distintos griegos y los distintos bárbaros. Quiénes propugnaban esas ideas eran un pequeño círculo, la mayoría extranjeros, que no intervenían en la política ateniense, pero transmitían sus ideas a la juventud de Atenas, a la que enseñaban los filósofos y sobre todo los sofistas.

También fueron creándose discrepancias entre los propios sofistas sobre el verdadero poder del logos, sobre la relación de justicia y nomos y sobre el verdadero valor de las leyes existentes, para algunos meramente convencionales, ni mejores ni peores que la de los bárbaros, lo que supone una desacralización y contribuye a disminuir la adhesión afectiva, mucho más fuerte.

Nótese que hasta ahora no se ha hablado de libertad. Siguiendo a Rodríguez Adrados ${ }^{10}$.

«En la ciudad democrática, la ley escrita es garantía de la libertad.

Este concepto de libertad, el disfrutar de una autonomía personal limitada y protegida por la ley de la ciudad, es una extensión del concepto anterior de la libertad por oposición a la tiranía: a la de un conquistador extranjero, a la de un tirano o rey despótico. O al dominio del amo sobre el esclavo».

En la democracia ateniense la libertad está muy relacionada con la parresía o libertad de palabra. Posteriormente el ideal de libertad se transfirió al de la libertad interior, a la libre conciencia. Pero también se exalta la libertad en la vida privada, la aspiración a una vida exenta de censuras y críticas (y que arranca de la limitación 
de las funciones del Areópago, entre las que estaba la censura de la vida de los ciudadanos). Esta idea de libertad facilitará el alejamiento de la vida pública y la retirada a la vida privada en los momentos de decadencia ${ }^{11}$.

\section{La democracia liberal y representativa}

Benjamín Constant, en su conferencia pronunciada en el ateneo de París en 1819, "De la libertad de los antiguos comparada con la de los modernos", expresa de manera clara y breve una de las diferencias de valores entre las democracias de la Edad Antigua y las democracias liberales surgidas tras las revoluciones americana y francesa. Constant basa la democracia liberal en las libertades individuales y en la defensa de la esfera privada: con el aumento de los ciudadanos y de la división del trabajo se introduce una mayor heterogeneidad social y cultural, lo que da lugar a intereses y formas de vida diferenciadas, particulares, tan legítimos unos como otros. La esfera privada se amplía al tiempo que la pública se encoge. El gobierno debe proteger ese espacio de la libertad individual. En las democracias antiguas la ciudad, la polis, era lo más importante, el cuerpo social recubría por entero al individuo, que era secundario. La esfera pública era muchísimo más amplia que la privada. En la democracia liberal la vida social se estructura en dos ámbitos diferentes: el público, que regula los asuntos concernientes al interés general, y el individual, en el que cada cual decide sobre sus intereses particulares, y en el que se disfruta en privado del bienestar y el reposo que ofrece la vida en las sociedades modernas ${ }^{12}$. Para Constant, el modelo de las antiguas democracias, "de fuerte integración comunitaria, de democracia directa y de sometimiento del individuo al estado, ya no resulta ni deseable ni posible"13. Los derechos y las libertades individuales limitan el poder de la sociedad y del gobierno. Esta es una de las características de la democracia liberal: la de un gobierno o un poder limitado. Constant defiende limitar la autoridad y el ejercicio del poder, y para ello propone dos vías de actuación: fomentar los valores o principios que deban inspirar a la política moderna y construir y defender las instituciones que deban encarnarlos. Una medida concreta que propone es dividir el poder, diseminarlo en distintas instancias para que se frenen unas a otras siguiendo el modelo de Montesquieu ${ }^{14}$.

La característica más definitoria de la democracia liberal es la del "gobierno ejercido por medio de representantes libremente elegidos entre una pluralidad de candidatos" $" 15$. Las elecciones son, por tanto, un elemento imprescindible en una democracia liberal. El proceso electoral resulta ser un mecanismo que produce representación, produce gobierno y produce legitimidad. Pero los sistemas de elección pueden ser múltiples. El sistema electoral no es un mecanismo neutro, sino que es resultado de los juegos de poder. Los sistemas electorales incluyen a la vez sistemas que facilitan y sistemas que dificultan el acceso al ejercicio del poder. Hay modos de elección que facilitan la competitividad más que otros, 
considerándose, por ello, más democráticos. Vallès y Bosch destacan los siguientes requisitos como una forma de garantizar una competición justa ${ }^{16}$ :

- sufragio universal

- convocatoria regular y periódica de elecciones

- libertad de asociación para presentar candidatos

- igualdad tendencial de oportunidades de los candidatos para el acceso a los medios de información y publicidad

- neutralidad del gobierno en la organización del proceso electoral

- garantías para una libre emisión del voto (ausencia de coacciones, protección del secreto)

- recuento público de los votos emitidos

- existencia de unas normas preestablecidas para la adjudicación de los puestos entre los candidatos

- existencia de una instancia independiente para dirimir los conflictos

Las elecciones son una forma de regular el acceso al poder político. Pero el proceso electoral no es solo una forma de acceder a dicho poder, se concibe también como una forma de "expresar una delegación de facultades políticas a favor de determinados ciudadanos"17, que son los que acceden al poder político, quedando de esta forma legitimados para su ejercicio. Es decir, los elegidos son representantes. ¿Pero de qué naturaleza es esa representación? ¿Representantes de qué o de quiénes? Puede tratarse de una representación de intereses, o de opiniones, o de valores; o puede ser también una representación territorial, o personal, o una representación de clase o de cualquier otro grupo (religioso, profesional, étnico, etc.).

Muchos autores distinguen entre representación y representatividad. La representatividad es considerada otro valor democrático. Las diferentes personas y grupos tienen intereses, valores, etc, distintos, e incluso contrapuestos. Una forma de integrar a las minorías y aumentar la legitimidad del gobierno es incorporándolas a través de mecanismos de representitividad. De lo que se trata es de reproducir el equilibrio o estado de fuerzas, intereses o identidades que se da en la base en los órganos de decisión.

Otra característica de la democracia liberal y representativa es la responsabilidad de los que ejercen el poder, si bien la teoría de la representación política rechaza el "mandato imperativo". Como dice Giovanni Sartori,

Aunque en el ámbito de la política el representante ni tiene un principal concreto y perfectamente identificable, la representación electiva trae consigo: a) receptividad (responsiveness), los parlamentarios escuchan a su electorado y ceden a sus demandas, b) rendición de cuentas (accountability), los parlamentarios han de responder, aunque difusamente, de sus actos, y c) posibilidad de destitución (removability), si bien únicamente en momentos determinados, por ejemplo mediante un castigo electoral ${ }^{18}$. 


\section{Otras teorías de la democracia actuales}

Schumpeter critica la idea del bien común en el que se basaba el ideal democrático del siglo XVIII y XIX ${ }^{19}$. En primer lugar, dirá, no hay bien común, unívocamente determinado, en el que todos los individuos y grupos puedan estar de acuerdo. En segundo lugar, aun cuando se lograse definir un bien común que resultase aceptable para todos nos quedaría por resolver otro problema: lograr el acuerdo en el camino o en los medios a seguir para alcanzar dicho bien común. Schumpeter critica la idea según la cual

"el pueblo" tiene una opinión definida y racional sobre toda cuestión singular y que lleva a efecto esta opinión -en una democracia- eligiendo "representantes" que cuidarán de que esa opinión sea puesta en práctica.

Así, pues, la elección de los representantes se considera como el fin que se subordina al fin primario del sistema democrático, que consiste en investir al electorado del poder de decidir las controversias políticas.

E invierte los términos: en una democracia el papel del pueblo es el de elegir a un gobierno, bien directamente o indirectamente (como por ejemplo a través de un Parlamento $)^{20}$, y este gobierno será el que defina los problemas y decida sobre las distintas cuestiones. Para Schumpeter la democracia no se define por una serie de valores, sino que la democracia es un procedimiento de alcanzar el poder político, procedimiento que consiste en "una lucha de competencia por el voto" Los programas, las propuestas e incluso la defensa de determinados valores se conciben como subproductos de la lucha por la conquista del poder ${ }^{21}$.

Robert Dahl prefiere hablar de poliarquía en vez de democracia para hablar de nuestro sistema, cuya politeya consiste en realidad en un conjunto de centros de poder y autoridad, y que además no siempre están controlados por la ciudadanía. Dahl considera que" no hay en la realidad ningún régimen, de dimensión considerable, totalmente democratizado" 22 , por lo que la democracia sería para él un tipo ideal al que aspirar. Prefiere hablar en términos comparativos, de sistemas más o menos democráticos. Para este autor dos son esencialmente las dimensiones que caracterizan la democracia: la participación y la representación. Para que en la práctica se de una democracia real, Dahl fija cinco condiciones: la participación de todos los ciudadanos (de todos los miembros de la organización en nuestro caso) en los procesos de toma de decisiones, la igualdad del voto en el momento de adoptarlas, el acceso a la información para poder elegir entre las distintas opciones, el control por parte de los ciudadanos (de los miembros de la organización) de los asuntos que deben ser incorporados a la agenda pública de debate, y la inclusión de todos los adultos en los derechos de ciudadanía. Dahl compara los distintos sistemas "de acuerdo con la amplitud con que facilitan la oposición, el debate público o la lucha política" ${ }^{23}$, para valorar cual es más o menos democrático.

Tanto Dahl como Schumpeter destacan, pues, otro rasgo de la democracia: la competitividad. 
Para otros autores, la democracia es una especie de religión política, y como cualquier otra ideología no es más que una oportunista invención retórica, que surge como subproducto estratégico de las luchas por el poder. En esta línea se sitúa, por ejemplo, Markoff.

\section{EL PAPEL DE LAS ORGANIZACIONES}

Para Michels "la organización es el único medio para llevar adelante una voluntad colectiva" 24 . Sin embargo, definir las organizaciones y explicar su desarrollo atendiendo sólo a su papel de mecanismos para perseguir objetivos o fines comunes plantea de nuevo los problemas, tratados anteriormente, del bien común, de la voluntad común y del hombre como un ser totalmente racional.

Las organizaciones, asociaciones y movimientos son también importantes factores estructuradores de la identidad individual y colectiva. Muchas veces, la adhesión del individuo a la organización tiene un importante componente irracional y afectivo. Este tipo de adhesión suele ser además la más estable. Por identidad entiendo lo mismo que Castell $\mathrm{s}^{25}$ : "el proceso de construcción del sentido atendiendo a un atributo cultural, o un conjunto relacionado de atributos culturales, al que se da prioridad sobre el resto de las fuentes de sentido." El sentido lo define como la “identificación simbólica que realiza un actor social del objetivo de su acción.” La construcción de la identidad -continua Castells- siempre tiene lugar en un contexto marcado por las relaciones de poder. La construcción de la identidad supone un proceso de autodefinición e individualización.

"La construcción de las identidades utiliza materiales de la historia, la geografía, la biología, las instituciones productivas y reproductivas, la memoria colectiva y las fantasías personales, los aparatos de poder y las revelaciones religiosas. Pero los individuos, los grupos sociales y las sociedades procesan todos esos materiales y los reordenan en su sentido, según las determinaciones sociales y los proyectos culturales implantados en su estructura social y en su marco espacial/temporal."26

Para Castells, "la tendencia social y política característica de la década de los noventa es la construcción de la acción social y política en torno a identidades primarias" 27. Muchos de los movimientos actuales "no sólo buscan diversas metas instrumentales, sino la afirmación de identidades excluidas como públicamente buenas" y políticamente correctas. "La fragmentación social se extiende, ya que las identidades se vuelven más específicas y aumenta la dificultad de compartirlas."

Se dice que estamos en la sociedad de la organización o sociedad organizada. Como dice Mayntz, "la organización en una esfera ha producido como reacción la formación de organizaciones en otros sectores. Por otra parte, y continuo con Mayntz, las estructuras de aquellas organizaciones que en su actividad, o en la persecución de sus objetivos y en el seguimiento de su estrategia tienen que mantener una relación 
recíproca continua con otras organizaciones, tienden a asemejarse a las estructuras de esas otras organizaciones, aliadas o adversarias ${ }^{28}$.

La forma que adopta la sociedad en la era de la información es la de la sociedad red: cada vez más, las organizaciones e instituciones, y los procesos sociales dominantes, se organizan en redes de geometría variable. Castells define la red como un conjunto de nodos interconectados entre sí. La morfología de las redes supone una reorganización de las relaciones de poder: los conmutadores que conectan las redes son ahora las fuentes de las que deriva el poder. "Puesto que las redes son múltiples, los códigos y conmutadores que operan en ellas se convierten en las fuentes fundamentales para estructurar, guiar y confundir a las sociedades". Ahora "el poder de los flujos tiene prioridad sobre los flujos de poder". Asistimos a una "preeminencia de la morfología social sobre la acción social"29.

\section{Rasgos que caracterizan a toda organización}

Las organizaciones movilizan recursos para lograr fines, es decir, las organizaciones están orientadas hacia fines u objetivos (sin que entremos ahora aquí a distinguir entre fines oficiales y fines reales); presentan siempre una determinada división del trabajo, lo que supone una estructura diferenciada horizontal y verticalmente, lo que, a su vez, conlleva un sistema de papeles individualmente asignados y que no están ligados personalmente a los miembros concretos que la integran en un momento dado ${ }^{30}$.

\section{Los fines de la organización}

El primer problema que se plantea, pues, es el de los fines de la organización. Toda organización, sobre todo en el caso de las asociaciones voluntarias, declara unos fines oficiales en los que pretende basar su legitimidad. Dichos fines suelen ser tan vagos y utópicos que muchos autores consideran que no influyen para nada en la estructura ni en el comportamiento de la organización, no siendo más que una fachada. Así por ejemplo, Panebianco, en su estudio sobre los partidos políticos, advierte contra el prejuicio teleológico. Dicho prejuicio consiste en la atribución de fines a priori a los partidos y en la creencia de que dichos fines constituyen su razón de ser. Según la versión del prejuicio teleológico, tanto las actividades como las características organizativas se deducirán de los fines ${ }^{31}$.

Por otro lado, tenemos también la tesis de Michels, según la cual conforme va consolidándose la organización se van olvidando los fines para los que surgió, pasando a un primer plano la conservación de dicha organización. Es decir, el fin oficial se sustituye en la práctica por otro fin: el mantenimiento de la organización. Ésta pasa a ser un fin en sí misma ${ }^{32}$.

En esta línea se sitúa también la tesis de James March y sus colaboradores, 
que concibe las organizaciones como cubos de basura, en las que los problemas y los retos definidos y elegidos son receptáculos adecuados para que los individuos y los grupos arrojen a ellos soluciones que mejoren sus posiciones. Es decir, los objetivos y los fines de la organización son los medios de los que se sirven los individuos y grupos para mejorar sus posiciones, son subproductos estratégicos de las luchas de poder.

... las metas están ahí para dar sentido a adaptaciones no planificadas y a desarrollos accidentales, con lo que más que planes racionales de acción son racionalizaciones de encuentros no predecibles con intereses diversos y cambiantes. ${ }^{33}$

Es cierto que los fines oficiales, que suelen proceder del modelo originario de la organización, no condicionan de una forma inmediata y automática las actividades y la estructura de la organización, ni mucho menos, pero tampoco cabe duda de que los fines oficiales son un límite, más o menos lejano, a las actividades organizativas. Es decir, si bien el margen de maniobra que permiten los fines oficiales es muy amplio dicho margen existe. Los fines tienen un carácter legitimador, a través de ellos los miembros justifican la existencia de su organización y su pertenencia a la misma. Los fines oficiales o declarados forman parte de las señas de identidad de la organización, por lo que también son un material importante para la construcción de la identidad colectiva e individual. Como dice Castells ${ }^{34}$, "las identidades organizan el sentido, mientras que los roles organizan las funciones". En las asociaciones voluntarias los fines suelen apelar a un valor o un sistema de valores. Y los valores son creencias a cerca de lo que es bueno y deseable, por lo que la adhesión que provocan no tiene un origen racional o lógico, sino afectivo. Por tanto los fines cumplen un importante papel en la estructuración de la identidad colectiva e incluso de las identidades individuales, lo que supone una fuente importante de lealtad, y, como señala Hirschman, la lealtad es un factor decisivo para la persistencia de las organizaciones, sobre todo en los momentos difíciles, pues la lealtad activa el mecanismo de la voz de los miembros y previene su salida en los momentos adversos ${ }^{35}$. Por tanto, siguiendo a Panebianco

«las ineludibles funciones internas y externas de los fines oficiales obligan a desarrollar un cierto grado de actividad en relación con ellos, dado que a esta actividad va unida la identidad colectiva $\mathrm{e}$ incluso [...] la legitimidad del liderazgo»». ${ }^{36}$

\section{LA DIVISIÓN DEL TRABAJO}

En toda organización relativamente institucionalizada existen esferas específicas de competencia, es decir, una división del trabajo, de las normas y del poder, estableciéndose las atribuciones de cada uno y los medios para obligar. Las tareas organizativas están especializadas y diferenciadas, es decir, se da una división 
horizontal del trabajo, una departamentalización, donde las actividades son distribuidas a través de cargos y funciones. La división del trabajo está relacionada con los fines y objetivos de la organización, y al igual que ocurría con éstos, podemos encontrar una división del trabajo formal y otra informal.

La complejidad de la organización depende de la división de funciones y tareas asignadas, la cual depende a su vez de los fines y objetivos, de la heterogeneidad de los miembros, de la complejidad del ambiente en el que se ubica la organización y del pasado organizativo.

La división del trabajo es una de las principales causas por las que cada miembro de la organización (y cada unidad o división de la misma) adopta una visión particular de los objetivos. Existe una fuerte tendencia a considerar el objetivo parcial -intermedio- que se ha asignado a cada individuo o departamento como si fuera el objetivo principal, global, es decir, aquel que justifica la razón de ser de la organización. De esta forma cada uno tiene su propia jerarquía de objetivos y actúa en consecuencia. Y es que no podemos considerar los fines de la organización como algo dado, que existe al margen de los individuos y de los grupos, fuera de ellos, de tal forma que lo único que hacen es adoptarlos o seguirlos. Nada más lejos: la organización cobra vida realmente a través de los objetivos parciales y racionalidades limitadas de los individuos y los grupos que hay en su seno ${ }^{37}$.

En todas las organizaciones, junto a la diferenciación horizontal, encontramos una diferenciación vertical, es más, la una implica la otra, pues la mera distribución de tareas y responsabilidades genera formas de poder y control.

Como hemos dicho anteriormente con la división del trabajo se tiende a que los individuos y grupos desarrollen valores, objetivos e intereses particulares, distintos de los de la organización globalmente considerada. Pues bien, la jerarquía o estructura de autoridad sirve para coordinar y canalizar, y para determinar quien ha de decidir en caso de ambigüedad. Cuanto mayor sea la división del trabajo mayores serán las necesidades de coordinación y canalización. Mientras no exista conflicto ni incertidumbre apenas se recurrirá a los canales jerárquicos, pues, como apunta Perrow siguiendo a Wilfred Brown, una de las funciones más importantes de la jerarquía consiste en resolver las disensiones o las situaciones de ambivalencia ${ }^{38}$. Por tanto, una forma de coordinar las distintas actividades y departamentos es a través de la jerarquía. La jerarquía es una forma de ejercer el control. Se trata, en palabras de Mayntz, de una «división entre facultades de decisión y de mando establecidas en reglas y papeles, de una parte, y las obligaciones de ejecución y obediencia, de la otra $\rangle^{39}$. En toda organización hallaremos, por tanto, una estructura de autoridad, pues, como dice Charles Perrow, un cierto grado de jerarquía tiene que existir en cualquier contexto organizado ${ }^{40}$.

Una organización puede estructurarse de forma jerárquica, con canales de mando que discurren de arriba abajo, siendo en la cabeza donde se toman las decisiones sobre las actividades encaminadas directamente al objetivo y donde se 
decide sobre el objetivo mismo; o puede estructurarse «según los principios democráticos, en los que los miembros deciden en común sobre los objetivos y las actividades, y la autoridad se delega de abajo arriba" ${ }^{41}$.

La jerarquía es una forma de ejercer el control. Las organizaciones emplean distintas estrategias para ejercer el control. Así, se puede recurrir a la supervisión directa -personal- o utilizar reglas y reglamentos para ejercer ese control. La primera forma es más discrecional, lo que otorga un mayor poder a los superiores jerárquicos, pero también es más flexible por cuanto que permite una respuesta rápida ante cualquier imprevisto. La segunda ofrece mayor certidumbre, resta a los superiores arbitrariedad, pero introduce mayores rigideces. También se pueden combinar ambas formas, de esta manera, para algunas actividades se realizará un control personal y para otras el control se ejercerá a través de la reglamentación, o en determinados niveles o áreas predominará una forma y en otros otra.

\section{FORMALIZACIÓN Y BUROCRATIZACIÓN}

El concepto de formalización expresa el grado en que las actividades y relaciones de una organización están determinadas por reglas o normas firmemente establecidas. Organizar implica crear normas generales o duraderas para la actuación dirigida a un fin ${ }^{42}$. Organizar implica "reglar". Siguiendo a Crozier, la organización es el instrumento del que los actores se han dotado para "reglar" sus interacciones con el fin de obtener el mínimo de cooperación necesaria para la persecución de objetivos $\operatorname{colectivos}^{43}$. La burocratización hace referencia al grado de regulación de los procedimientos.

Toda organización cuenta con unas reglas. Cuanto mayor es la complejidad de la organización más necesarias se hacen las reglas. La regla proporciona un patrón, sirve de orientación a la hora de actuar o tomar decisiones, sobre todo cuando estamos en una encrucijada, es decir, cuando se presentan varias alternativas y se carece de razones evidentes para elegir una u otra. Las organizaciones complejas necesitan de algunas reglas para economizar trabajo (evitando por ejemplo que dos individuos realicen el mismo trabajo), establecer prioridades que no son evidentes, fijar criterios para la distribución de recursos, coordinar y canalizar el esfuerzo, etc. Las reglas constituyen también una forma de limitar la discrecionalidad y asegurar un mínimo de coordinación y cooperación. Por tanto las reglas pueden ser también una forma de garantía democrática en el seno de una organización. Recordemos que en una de nuestras definiciones, un gobierno limitado era una condición sine qua non para la democracia.

Las organizaciones generan poder y el control y utilización de este poder son problemas organizacionales vitales ${ }^{44}$. En la persecución de los fines oficiales o legítimos, los grupos o individuos pueden beneficiarse de esos excedentes que genera la organización, y utilizarlos para asegurarse la cooperación, distribuyendo parte 
de los mismos entre sus seguidores. Como esos recursos son escasos, se establecen luchas de poder o competencias que constituyen un factor de disgregación para la organización. Pues bien, las reglas o normas son también una forma de poner límite a estos procesos centrífugos, evitando así la autodestrucción de la organización.

Pero las reglas plantean un gran inconveniente, y es que tanto las organizaciones como sus entornos suelen cambiar con mayor rapidez que las mismas reglas. Por tanto puede ocurrir que una regla tenga aún vigor y sin embargo la situación para la que fue diseñada ya no exista. En este caso, la regla, en vez de ayudar entorpece. Por esta razón las normas pueden convertirse en armas de doble filo: por una parte protegen de la arbitrariedad a quienes están sujetos a ellas, pero a su vez también restringen su acción; sirven para coordinar pero pueden acabar bloqueando; canalizan el esfuerzo a la vez que lo inhiben; garantizan el seguimiento de criterios universalistas al mismo tiempo que posibilitan el refugio de los incompetentes; etc. ${ }^{45}$.

Si partimos desde un enfoque estructural, las normas serán consideradas como un elemento de la estructura, y por tanto relativamente estable, que condiciona, orienta o restringe las acciones de los miembros de la organización partidista. Según este punto de vista, las normas se elaboran inicialmente para alcanzar los objetivos de la organización, para evitar desviaciones y asegurar la coordinación. Pero puede ocurrir que las normas reemplacen a los objetivos, es decir, que se conviertan en un fin en sí mismas. También puede darse el caso de que las normas se empleen para lograr objetivos particulares, como por ejemplo desplazar a un líder por parte de algún grupo determinado. Por otra parte, también podemos encontrarnos con normas o reglas que en la práctica no se siguen, y esto también resulta muy significativo, por lo que además de analizar las normas es conveniente también analizar el grado de cumplimiento de las mismas.

Otro punto de vista es el que nos proporciona el análisis estratégico. En este caso, las normas son consideradas como un producto de las luchas de poder de los actores, es decir, son fruto de una situación determinada en el espacio y en el tiempo, de una situación histórica, y reflejan, por tanto, el poder que los grupos e individuos han alcanzado y que tratan de mantener, de ahí su interés en "normalizarlo".

Para Crozier, que defiende el enfoque estratégico, la organización no es más que un universo de conflicto, y su funcionamiento el resultado de confrontaciones entre las racionalidades limitadas, múltiples y divergentes de actores relativamente libres, que utilizan los recursos y las fuentes de poder a su alcance ${ }^{46}$. Este autor cuestiona la idea de los "objetivos comunes" en las organizaciones, es decir, no considera necesario, o al menos suficiente, que los participantes se adhieran a los objetivos de una organización para que ésta funcione o se mantenga. El quid de la cuestión estriba no sólo en integrar todas las actividades indispensables para la persecución de un resultado, sino también en integrar las relaciones de poder y las estrategias de los actores que aseguren la ejecución de estas actividades. Los actores 
tienen sus propias estrategias personales, divergentes y a menudo contradictorias, con las que tratan de proteger o aumentar su margen de libertad reduciendo su dependencia de los demás y aumentando la dependencia de los demás con respecto a ellos. ¿Qué papel tienen entonces las reglas o las normas? El de introducir un mínimo de certidumbre definiendo las normas del juego. Las normas regulan los conflictos e intercambios entre los diversos participantes. Las reglas limitan la libertad de acción de los participantes definiendo o restringiendo los resultados posibles que los participantes pueden perseguir y/o los medios de lograrlos. Las reglas o normas organizacionales deben constreñir a todos los miembros (isonomía), lo que no quiere decir que les afecten a todos por igual. Las reglas no son neutras: privilegian a determinados actores en detrimento de otros, y al mismo tiempo que reducen la incertidumbre por un lado generan zonas de certidumbre por otro que son utilizadas por los actores en presencia de forma simultánea, bien para defender sus posiciones, bien para mejorarlas. Por eso las reglas son tan importantes, y su modificación no supone sólo cambiar unas normas escritas por otras o dibujar un nuevo organigrama, sino que supone reestructurar los sistemas de acción redistribuyendo las zonas de incertidumbre cruciales o los recursos y fuentes de poder que los diferentes grupos pueden movilizar en el seno de la organización en sus intercambios ${ }^{47}$. Por eso para valorar el grado de democracia en las organizaciones también resulta crucial el hecho de quién elabora las reglas, quién las aprueba y cómo se llevan a cabo ambos procesos.

La formalización y la estandarización hacen más previsible el comportamiento y facilitan el control externo. Siguiendo a Mayntz, una organización está tanto más formalizada, en sentido sociológico, cuanto más definidas se hallen las actividades dirigidas a un fin mediante reglamentaciones organizativas relativamente estables o duraderas ${ }^{48}$. La eficacia de una mayor o menor formalización dependerá de la forma de dominación que se de en la organización, de la manera en que los miembros se ligan a la misma, del objetivo u objetivos de dicha organización y del ambiente en que opere y de su grado de apertura al mismo. Efectivamente, tal y como se apunta en las teorías de la organización, la regulación o formalización sólo será funcional para aquellos procesos rutinarios o que se repiten de una forma más o menos regular. Por tanto, cuanto más abierta sea una organización y más turbulento e imprevisible sea el ambiente en el que opera, menos funcional resultará la formalización. Del mismo modo, si el objetivo de la organización es muy vago y genérico y no es susceptible de ser desdoblado en cometidos que permanezcan constantes, sino que por el contrario exige que las actividades se adapten a situaciones constantemente cambiantes, la formalización debe ser escasa para garantizar una rápida adaptación de la organización. En tercer lugar, si la organización de la que se trata es una asociación voluntaria, en la que el vínculo de los miembros con la organización es relativamente débil y, por tanto, resulta muy difícil saber con seguridad con cuantos miembros se puede contar y 
para qué cosa, por cuanto tiempo y con qué intensidad se van a emplear, una excesiva formalización acarreará una gran ineficacia. Aquí, la clave está en lograr el compromiso de los miembros, bien a través de incentivos colectivos o de identificación, bien a través de incentivos selectivos o de interés, o aprovechando la presión social que ejerce un grupo ya comprometido sobre el individuo de ese grupo. Por último, sólo queda comentar cómo influye la forma de dominación sobre la formalización, y creo que resulta obvio que cuanto más predominante sea el tipo de dominación legal-racional más sentido tendrá la formalización, pues la autoridad legal-racional se basa en la idea de que la ley o la norma es la fuente de la legitimidad, por encima de grupos o individuos concretos.

\section{LAS NORMAS NO ESCRITAS: LA CULTURA DE LA ORGANIZACIÓN}

Por supuesto que las normas escritas no agotan el universo normativo de la organización. A veces, las pautas de conducta socialmente aprendidas, arraigadas en el seno de la organización, son más decisivas a la hora de explicar el comportamiento organizativo de los individuos y los grupos. La cultura de la organización es, pues, otro factor, y muy importante, que actúa como condicionante de la acción social de los actores.

Tal y como señala el enfoque estructural-funcionalista, el actor se orienta en su acción tanto por "motivos" o intereses como por "valores". Las normas y los valores culturales ejercen una coerción sobre el individuo. La socialización es el proceso por el que los individuos aprenden los valores, las normas, el uso de los símbolos, el lenguaje, etc., es decir, todo lo necesario para desenvolverse en el entramado social, o, en nuestro caso, en la organización. Por tanto, en aquellas organizaciones donde existe una subcultura fuerte, se desarrollarán sus propios mecanismos o procesos de socialización, en los que la adhesión a los valores, normas, etc., conlleva una gran carga afectiva. Mientras que en las organizaciones de subcultura débil, ese proceso de aprendizaje suele ser más racional, con menos carga afectiva. Luego, incidir en el plano moral y simbólico fomentando los valores democráticos tanto desde fuera como desde dentro de la organización, será también una forma de lograr una mayor democracia en las organizaciones.

La importancia de los elementos culturales tampoco es puesta en duda por el enfoque estratégico, aunque aquellos se analizan desde una óptica diferente de la de la teoría estructural-funcionalista, muy criticada por el análisis estratégico. En el enfoque estratégico la integración de las conductas de los actores, a diferencia del enfoque estructural-funcionalista, no es interpretada como la consecuencia directa del aprendizaje de un conjunto de comportamientos interdependientes con sus propias normas y valores, sino que estos elementos culturales forman parte de los recursos o de los constreñimientos que se encuentran los actores, forman parte de la situación total en la que se halla el actor, son elementos de esa situación (como también lo son 
el resto de actores con sus intereses, objetivos y estrategias). El enfoque estructuralfuncionalista hace hincapié en la adaptación, la cual se consigue con una correcta socialización. El análisis estratégico critica este enfoque por estático, y porque el comportamiento organizativo de los individuos y grupos es visto únicamente como consecuencia de una adaptación pasiva de aquéllos a las normas y demás elementos culturales. Para el enfoque estratégico las normas no es sólo algo a lo que haya que adaptarse para lograr la integración, sino que es algo también con lo que se puede “jugar”, un elemento más del juego, y la integración es la consecuencia de ese juego ${ }^{49}$.

\section{EL PODER ORGANIZATIVO}

El concepto de poder es muy ambiguo, por lo que conviene aclarar qué es lo que se entiende aquí por tal. En sociología suelen manejarse tres acepciones de poder: a)el poder como fuerza opresiva, b) el poder como autoridad "que se posee por razones de tradición, carisma, ascendencia moral, cargo público u otras causas y que no se ejerce con violencia", y c) el poder como capacidad de influencia en la acción de otros. Nuestro concepto de poder organizativo estaría en la línea de la última acepción ${ }^{50}$.

García Madaria define el poder como una relación de intercambio asimétrico entre varios actores ${ }^{51}$. Se trata de una relación y no de un atributo como puede ser la edad o el sexo. En esta relación de intercambio no existe la igualdad (ya que si así fuera no se trataría de poder), sino que siempre hay alguno que tiene ventaja. Siguiendo el esquema que plantea García Madaria A tiene poder sobre B si ${ }^{52}$ :

1) A controla recursos estratégicos para la actividad de B;

2) B no controla recursos estratégicos para la actividad de A (de no ser así la relación no sería asimétrica, sino simplemente de intercambio, y por tanto no podríamos hablar de poder);

3) B no tiene otras fuentes a las que acceder para obtener el recurso que $A$ controla, o dicho acceso es más costoso que la relación con A;

4) B no tiene capacidad coercitiva para apropiarse los recursos que $\mathrm{A}$ controla, es decir, no puede usar la fuerza (incluida la "fuerza legal") contra A bien porque no la tiene bien porque su uso acarrearía mayores costes que la relación establecida con A;

5) B no puede o no está dispuesto a reducir su necesidad de recursos que A controla.

Por tanto, dentro de una organización un actor está en situación de poder sobre otro, si el primero controla recursos estratégicos para la actividad del segundo. Existen una serie de actividades en cada organización que son imprescindibles para el correcto funcionamiento de la misma. Además, la forma en que se llevan a cabo dichas actividades condiciona a la organización. De ahí su carácter estratégico. El control de estas actividades y/o de los ámbitos en que se desarrollan otorga un gran poder organizativo. Cuanto mayor importancia tenga para la organización una actividad mayor será el poder de aquel o aquellos que controlen dicha actividad. 
Las organizaciones tratan de regular dichas actividades, así como los ámbitos organizativos en los que se desarrollan, con el fin de controlar a los encargados de las mismas, limitando así su grado de discrecionalidad. Cuanto mayor sea el grado de institucionalización ${ }^{53}$ de la organización mayor será la regulación de esas actividades y, por tanto, mayor será su predecibilidad. Pero la regulación de todos los aspectos es imposible, nunca existirá, ni mucho menos, una previsión perfecta y absoluta, por lo que siempre hallaremos zonas de incertidumbre ${ }^{54}$. El control de estas zonas de incertidumbre es lo que proporciona situaciones de poder. Cuanto más importante sea para la organización la actividad donde se da una zona de incertidumbre mayor será el poder que se derive del control de dicha zona. Los recursos empleados en los juegos de poder derivan, pues, del control de las zonas de incertidumbre.

La estructura de las comunicaciones está íntimamente relacionada con la distribución del poder en la organización. En primer lugar, la información es necesaria para tomar decisiones con miras a un fin, es decir, es un proceso de reducción de la incertidumbre que permite orientar la acción. En segundo lugar, solamente mediante el tratamiento y acceso a la información es posible insertarse en la vida social con eficacia ${ }^{55}$. El sistema de comunicación y transmisión de la información constituye, pues, una importante zona de incertidumbre. Quien controla dicho sistema puede imponer a los otros su propia definición de la situación. Esta es la concepción de la autoridad que tienen March y Simon, para los cuales el control de los medios para estructurar el entorno y las percepciones de los demás es una fuente importantísima de poder. Se trata de que los miembros vean "las cosas adecuadas y bajo la perspectiva adecuada"

\section{CONCLUSIONES : ¿CÓMO PROFUNDIZAR EN LA DEMOCRACIA?}

Nuestra sociedad es una sociedad de organizaciones, en este sentido se habla de sociedad organizada. Por otra parte, se ha alcanzado un grado de complejidad tal, una división del trabajo social y un crecimiento de la población que hace imposible cualquier experiencia de democracia directa. La sociedad es una organización de organizaciones, y democracia directa y organización son incompatibles, pues organización implica división del trabajo, y el poder y la jerarquía son inneherentes a la división del trabajo. ¿Cómo podemos, pues, profundizar en la democratización de la sociedad? Haciendo más democráticas las organizaciones, todas las organizaciones: políticas, económicas, culturales, etc. ¿Cómo lograrlo? Organización implica poder, ya lo hemos visto, no se puede evitar, lo que tenemos que hacer es que ese poder sea un poder:

limitado,

responsable,

elegido mediante de un sistema que facilite la competencia

y

representativo. 
Los fines, los objetivos y las normas organizativas limitan el ejercicio del poder: los fines y los objetivos condicionan, orientan, aunque sea escasamente, las acciones de los líderes. Por otra parte, las normas organizativas suponen un freno a la arbitrariedad del poder. Pero como decíamos en el apartado dedicado a la formalización, las normas pueden quedarse obsoletas y acabar siendo ineficaces, al tiempo que son producto de los equilibrios de poder que hubo en un momento dado, por lo que conviene regular también el cambio normativo, así como el proceso de elaboración y aprobación de las normas, y las estructuras que velen por su cumplimiento y sancionen su incumplimiento. El proceso de elaboración y aprobación de las normas debe ser participativo. Otro mecanismo para limitar el poder es el que apunta Constant siguiendo a Montesquieu: dividir el poder, diseminarlo en distintas instancias para que se frenen unas a otras.

Los que ejercen el poder han de ser responsables: deben responder, rendir cuentas, y ser receptivos o tener en cuenta al resto en la toma de decisiones o, al menos, en determinadas decisiones. Para ello habrá que arbitrar las normas e instituciones adecuadas que garanticen ese ejercicio de responsabilidad y receptividad.

La selección de los dirigentes debe hacerse a través de elecciones, y los procesos electorales deben cumplir los requisitos señalados por Vallés y Bosch ${ }^{57}$.

Otro rasgo característico de la democracia es la participación. Constant ya advertía contra uno de los peligros de la libertad moderna: "que absorbidos por el disfrute de nuestra independencia privada y por la búsqueda de nuestros intereses particulares, renunciemos con demasiada facilidad a nuestro derecho de participación en el poder político"s8. Muchas veces la participación se reduce para la mayoría de las personas a votar cada cierto tiempo en las elecciones para elegir a los representantes. Raimon Panikkar propone pasar de la arena al ágora:

«Arena es una palabra de origen etrusco que sugiere lucha, competición, victoria. La arena es la arena de los gladiadores. El ágora es el espacio donde se habla, se reúne, se discute, donde el enemigo -si se quiere utilizar esta palabra- es presentado: se le habla, se le acepta y se ve quién de los dos, de los tres o de los que sean, tiene razón. El ágora tiene que ver con la asamblea y con la iglesia». ${ }^{59}$

Debemos recuperar el cultivo de la palabra (de nuevo cobra importancia la parresía), el mecanismo de la voz (como diría Hirschman), para lo cual hay que facilitar las comunicaciones y el acceso a la información. Panikkar propone rescatar

«Aquella palabra que rompa el silencio, que crea hablando, que no se repite lo que se ha dicho en la escuela, la televisión o que está escrito en los diccionarios. Todas las lenguas vivas son dialectos que se han hecho en el habla de los padres con los hijos y de los amigos entre sí. Con el tiempo se van creando nuevas formas de hablar». ${ }^{60}$

Pero el modelo del ágora no es posible en una sociedad o en una organización masificada, por lo que una solución es la descentralización. Efectivamente, el tamaño 
deviene en un factor condicionante de primer orden, ya lo hemos visto. En palabras de Robert Dahl: "tanto el número de personas en una unidad política como la extensión de su territorio tienen consecuencias para la forma de la democracia" ${ }^{\prime 61}$. La solución está en crear una estructura organizativa en la que en las bases las personas decidan en común sobre los objetivos y las actividades, y la autoridad se delegue de abajo arriba. Es decir, una estructura organizativa en la que en los niveles más básicos adopten el modelo del ágora.

La importancia de la voz también ha sido señalada por Hirschman ${ }^{62}$, que la concibe "como un intento por cambiar un estado de cosas poco satisfactorio, en lugar de abandonarlo". La voz, por tanto, puede funcionar como una alternativa a la salida, es más, "la decisión de salida se tomará a menudo a la luz de las perspectivas de uso eficaz de la voz". Si se está convencido de que la voz será eficaz, es posible que se posponga la salida. Por tanto la voz no sólo es un requisito fundamental para que podamos hablar de democracia en una organización, sino que se puede concebir también como un instrumento para el mantenimiento y refuerzo de dicha organización. El recurso a la voz también depende del grado de dependencia que se tenga de la organización o del sistema: a mayor dependencia mayor uso de la voz. Y no me refiero a la dependencia económica o de posición solamente, sino también a la dependencia de tipo social y afectivo: las personas más identificadas con la organización o el sistema, o aquellas cuyos círculos de referencia y pertenencia más se restrinjan a la organización serán las que más recurran al mecanismo de la voz. Tal y como reconoce Hirschman, la política es el campo más característico de la voz.

Pero incidir sólo en los aspectos organizativos no es suficiente. Como dice Panikkar, la fuerza de la democracia reside en su mito: "la aureola positiva que adquirió la palabra después de la Revolución francesa la ha convertido en un mito, y esto explica que hoy casi todo el mundo quiera ser demócrata" ${ }^{93}$. En este sentido, Sartori advierte sobre el peligro de abandonar la idea del valor y propone educar en los valores. De la misma manera Constant proponía dos vías de actuación para el mantenimiento de la democracia: fomentar los valores o principios y construir y defender las instituciones que deban encarnarlos.

Hay que distinguir entre democracia como técnica de gobierno y democracia como valor o sistema de valores. Los valores -ya lo hemos dicho- son creencias a cerca de lo que es bueno y deseable, por lo que la adhesión que provocan no tiene un origen racional o lógico, sino afectivo. Las ideas se tienen, en las creencias se está, dirá Ortega y Gasset. Para que la democracia como técnica de gobierno funcione $\mathrm{y}$, sobre todo, para que perdure debe sustentarse en la democracia como valor generalizado y compartido por todas las partes. La democracia como valor es un fin en sí misma. El fin es el mito, en el que todos creen, las partes sólo discrepan sobre los medios para conseguir ese fin. Las instituciones forman parte de los medios. La institucionalización consiste en la concreción de valores genéricos en una estructura, unos roles y unas pautas de conducta o normas de acción. Las 
instituciones regulan las formas en que se persigue un valor: imponen unas maneras y sancionan otras. Para que la democracia como forma de gobierno funcione es necesario una estabilidad relativa en las instituciones, lo que no debe interpretarse como una oposición al cambio institucional. Las instituciones forman parte de las reglas del juego, y para poder "jugar" a la democracia tenemos que aceptar las reglas del juego. El juego implica siempre unas reglas. Ahora bien, el juego puede -y debe- evolucionar sin dejar de ser el mismo juego, pues lo que en realidad evoluciona son sus reglas. Lo mismo ocurre con la democracia. 


\section{NOTAS}

${ }^{1}$ Mayntz, R., (1987): Sociología de la organización, Madrid, Alianza, p. 11.

${ }^{2}$ Ver ibídem, p. 29.

${ }^{3}$ Ibídem, p. 34.

${ }^{4}$ Rodríguez Adrados, F., (1997): Historia de la democracia, Madrid, Temas de Hoy, p. 26.

${ }^{5}$ Ver Aristóteles, (1986): Política, Madrid, Alianza, p. 153.

${ }^{6}$ Sobre lo que sigue ver Rodríguez Adrados, F., op. cit.

${ }^{7}$ Solón fue nombrado Arconte el año 594 a. C. en Atenas.

${ }^{8}$ Rodríguez Adrados, F, op. cit.

${ }^{9}$ Citado por Rodríguez Adrados, op. cit., p. 166.

${ }^{10}$ Ibídem, pp 160 y ss.

${ }^{11}$ Ibídem.

${ }^{12}$ Sánchez-Mejía, M. L., (1992): Benjamín Constant y la construcción del liberalismo posrevolucionario, Madrid, Alianza, p. 170.

${ }^{13}$ Sánchez-Mejía, M. L., (1989): "Estudio preliminar" de la obra de B. Constant, Escritos políticos, Madrid, Centro de Estudios Constitucionales, p. XXXIII.

${ }^{14}$ Ibídem, p. XXXV y XXXVI.

${ }^{15}$ Vallès, J. M. y Bosch, A., (1997): Sistemas electorales y gobierno representativo, Barcelona, Ariel, p. 11.

${ }^{16}$ Ibídem, p. 15.

${ }^{17}$ Ibídem, p. 20.

${ }^{18}$ Sartori, G., (1999): "En defensa de la representación política", en Claves, núm. 91, abril 1999.

${ }^{19}$ Schumpeter, J. A., (1984): Capitalismo, socialismo y democracia, Barcelona, Folio, pp. 322 y ss.

${ }^{20}$ Ibídem, p. 343.

${ }^{21}$ Ibídem, p. 343 y 364.

${ }^{22}$ Dahl, R. A., (1989): La poliarquía, Madrid, Tecnos, p. 18.

${ }^{23}$ Ibídem, p. 14.

${ }^{24}$ Michels, R., (1983): Los partidos políticos, Buenos Aires, Amarrortu, vol. 1, p. 67.

${ }^{25}$ Castells, M., (1998): La era de la información, Alianza, Madrid, vol. 2, p. 28-29.

${ }^{26}$ Ibídem.

${ }^{27}$ Sobre esto y lo que sigue, Ibídem, vol. 1, pp. 48 y 49, y 29 y 31.

${ }^{28}$ Mayntz, R., op. cit., p. 29.

${ }^{29}$ Sobre esto y lo que sigue ver Castells, M., op. cit., vol. 1, pp. 505-507.

${ }^{30}$ Mayntz, R., op. cit., p. 26.

${ }^{31}$ Panebianco, A., (1990) Modelos de partido, Madrid, Alianza, p. 30.

${ }^{32}$ Michels, R., op. cit., vol. 2, p. 157 y 160.

${ }^{33}$ Perrow, Ch., (1993): Sociología de las organizaciones, Madrid, McGraw-Hill, 
p. 165.

${ }^{34}$ Castells, M., op. cit., p. 29.

${ }^{35}$ Hirschman, A. O., (1977): Salida, voz y lealtad, México, FCE.

${ }^{36}$ Panebianco, A., op. cit., p. 59.

${ }^{37}$ Crozier, M. y Friedberg, E., (1981): L'acteur et le système. Les contraintes de l'action collective, Paris, Editions du Seuil, pp. 93-94.

${ }^{38}$ Perrow, Ch., op. cit., p. 42.

${ }^{39}$ Mayntz, R., op. cit., p. 125.

${ }^{40}$ Perrow, Ch., op. cit., p. 37.

${ }^{41}$ Mayntz, R., op. cit., p. 126.

${ }^{42}$ Ibídem, p. 112.

${ }^{43}$ Crozier, M. y Friedberg, E., op. cit., p.196 y 197.

${ }^{44}$ Ch. Perrow, (1993) Sociología de las organizaciones, McGraw Hill, Madrid, p. 14. ${ }^{45}$ Ibídem, p. 32.

${ }^{46}$ Ibídem, p. 92.

${ }^{47}$ Sobre todo esto ver Ibídem, cap. 3.

${ }^{48}$ Mayntz, R., op. cit., p. 112.

${ }^{49}$ Esta es la crítica que hacen Crozier y Friedberg al análisis estructural-funcionalista. Ver Crozier, M. y Friedberg, E., op. cit., cap. 3.

${ }^{50}$ Giner, S.; Lamo de Espinosa, E. y Torres, C., (1998): Diccionario de Sociología, Madrid, Alianza.

${ }^{51}$ García Madaria, J. M., (1985): Teoría de la organización y sociedad contemporánea, Barcelona, Ariel, p 204.

${ }^{52}$ Ibídem.

${ }^{53}$ Sobre el concepto de institucionalización ver Panebianco, A., op. cit., pp. 114 y ss. ${ }^{54}$ Sobre el concepto de "zonas de incertidumbre", cfr. Crozier, M. y Friedberg, E., op. cit.

${ }^{55}$ Lucas Marín, A., (1997): "La formación para la participación y la comunicación en las organizaciones", en REIS, 77/78, enero-junio 1997, p. 264.

${ }^{56}$ Perrow, Ch., op. cit., p. 151.

${ }^{57}$ Ver el apartado correspondiente a La democracia liberal.

${ }^{58}$ Contant, B., op. cit., pp. 282-283.

${ }^{59}$ Panikkar, R., (1999): El espíritu de la política, Barcelona, Península, p. 207.

${ }^{60} \mathrm{Ibídem,} \mathrm{p.} 206$.

${ }^{61}$ Dahl, R., (1999): La democracia. Una guía para los ciudadanos, Madrid, Taurus, p. 123.

${ }^{62}$ Hirschman, A. O., op. cit.

${ }^{63}$ Ibídem, p. 182 y 183.

\section{BILIOGRAFÍA}

ARISTÓTELES, (1986): Política, Alianza, Madrid. 
ÁVILA FRANCÉS, M, (1998): “Aportaciones teóricas para el estudio de los partidos políticos como organizaciones", en Praxis Sociológica, núm 3, Azacanes, Toledo. BURKE, E., (1978): Reflexiones sobre la revolución francesa, Centro de Estudios Constitucionales, Madrid.

CASTELLS, M., (1998): La era de la información, Alianza, Madrid. CONSTAN, B., (1989): Escritos políticos, Centro de Estudios Constitucionales, Madrid. CROZIER, M. Y FRIEDBERG, E., (1981): L'acteur et le système, Éditions de Seuil, Paris.

DAHL, R. A., (1990): La poliarquía, Tecnos, Madrid.

(1992): La democracia y sus críticos, Paidós, Barcelona.

(1999): La democracia. Una guía para los ciudadanos, Taurus, Madrid.

GARCÍA MADARIA, J. M., (1985): Teoría de la organización y sociedad contemporánea, Ariel, Barcelona.

GINER, S., LAMO DE ESPINOSA, E. Y TORRES, C. (eds.), (1998): Diccionario de Sociología, Alianza, Madrid.

HELD, D., (1997): La democracia y el orden global. Del Estado moderno al gobierno cosmopolita. Paidós, Barcelona.

HIRSCHMAN, A. O., (1977): Salida, voz y lealtad, FCE, México. (1986): Interés privado y acción pública, FCE, México.

LUCAS MARÍN, A., (1997): "La formación para la participación y le comunicación en las organizaciones", en REIS, 77-78, enero-junio 1997, número monográfico sobre la Formación y las Organizaciones.

MAYNTZ, R., (1987): Sociología de la organización, Alianza, Madrid.

OLSON, M.,(1971): The Logic of Collective Action, Harvard University Press, Cambridge.

(1986): Auge y decadencia de las naciones, Ariel, Barcelona.

PANEBIANCO, A., (1990): Modelos de partido, Alianza, Madrid.

PANIKKAR, R., (1999): El espíritu de la política, Península, Barcelona.

PERROW, CH., (1993): Sociología de las organizaciones, McGraw-Hill, Madrid. RODRÍGUEZ ADRADOS, F., (1997): Historia de la democracia, Temas de hoy, Madrid.

ROTHSCHILD, J. Y WHITT, J. A., (1991): El lugar de trabajo cooperativo.

Posibilidades y dilemas de la democracia y la participación en las organizaciones, MTSS, Madrid.

SARTORI, G., (1999): "En defensa de la representación política", en Claves, $\mathrm{n}^{\circ} 91$, abril.

SCHUMPETER, J. A., (1984): Capitalismo, socialismo y democracia, Folio, Barcelona. TOCQUEVILLE, A. de, (1989): La democracia en América, Alianza, Madrid.

Touraine, A., (1995): ¿Qué es la democracia?, Temas de Hoy, Madrid.

VALLÈS, J. M. Y BOSCH, A., (1997): Sistemas electorales y gobierno representativo, Ariel, Barcelona.

WEBER, M., (1993): Economía y sociedad, FCE, Madrid. 